\title{
Implementation of strategies to prevent and treat postoperative delirium in the post-anesthesia caring unit
}

\section{A German survey of current practice}

\author{
Thomas Saller $^{1}(\mathbb{0}) \cdot$ Klaus F. Hofmann-Kiefer $^{1}$ (1) $\cdot$ Isabel Saller $^{2} \cdot$ Bernhard Zwissler $^{1} \cdot$ Vera von Dossow $^{3}$ (])
}

Received: 16 October 2019 / Accepted: 27 April 2020

(c) The Author(s) 2020, corrected publication 2021

\begin{abstract}
Postoperative delirium is associated with worse outcome. The aim of this study was to understand present strategies for delirium screening and therapy in German Post-Anesthesia-Caring-Units (PACU). We designed a German-wide web-based questionnaire which was sent to 922 chairmen of anesthesiologic departments and to 726 anesthetists working in ambulatory surgery. The response rate was 30\% for hospital anesthesiologists. 10\% (95\%-confidence interval: 8-12) of the anesthesiologists applied a standardised screening for delirium. Even though not on a regular basis, in 44\% (41-47) of the hospitals, a recommended and validated screening was used, the Nursing Delirium Screening Scale (NuDesc) or the Confusion Assessment Method for the Intensive Care Unit (CAM-ICU). If delirium was likely to occur, 46\% (43-50) of the patients were examined using a delirium tool. 20\% (17-23) of the patients were screened in intensive care units. For the treatment of delirium, alpha-2-agonists $(83 \%, 80-85)$ were used most frequently for vegetative symptoms, benzodiazepines for anxiety in 71\% (68-74), typical neuroleptics in 77\% (71-82\%) of patients with psychotic symptoms and in 20\% (15-25) in patients with hypoactive delirium. 45\% (39-51) of the respondents suggested no therapy for this entity. Monitoring of delirium is not established as a standard procedure in German PACUs. However, symptom-oriented therapy for postoperative delirium corresponds with current guidelines.
\end{abstract}

Keywords Recovery room $\cdot$ Post-anesthesia nursing $\cdot$ Postoperative complications $\cdot$ Delirium $\cdot$ Health care survey

$\begin{array}{ll}\text { Abbreviations } \\ \text { PACU } & \text { Post-Anesthesia Caring Unit } \\ \text { POD } & \text { Postoperative delirium } \\ \text { ED } & \text { Emergence delirium } \\ \text { RASS } & \text { Richmond Agitation Sedation Scale } \\ \text { NuDESC } & \text { Nursing Delirium Screening Scale } \\ \text { OR } & \text { Odds ratio } \\ \text { CI } & \text { Confidence interval }\end{array}$

Vera von Dossow

vvondossow@hdz-nrw.de

1 Department of Anaesthesiology, University Hospital, LMU Munich, Munich, Germany

2 Department of Intercultural Communications, LMU Munich, Munich, Germany

3 Institute for Anaesthesiology, Heart and Diabetes Center NRW, Ruhr University of Bochum, Georgstr. 11, 32545 Bad Oeynhausen, Germany

\author{
CAM-ICU Confusion Assessment Method for the Inten- \\ sive Care Unit \\ TURF Total unduplicated reach and frequency \\ analysis \\ ESA European Society of Anaesthesiology
}

\section{Introduction}

The recovery unit, also known as post-anesthesia caring unit (PACU), provides ongoing nursing and medical care by specially trained personnel until the patient has completely emerged from anesthesia. German guidelines postulate the permanent presence of an anesthesiologist. By all means, a trained anesthesiologist must be on short call [1].

\subsection{Delirium}

Postoperative Delirium (POD) may occur, especially in the elderly, in up to $50 \%$ of the patients and is accountable for 
increased mortality [2]. A recent study showed that up to $19 \%$ of post-surgical patients developed delirium at the ward [3], while $14 \%$ were already tested positive for delirium in the PACU in the same setting [4]. Already $10 \mathrm{~min}$ after PACU admission, a pathologic RASS or NuDeSc-Score, often described as emergence delirium (ED), was associated with later delirium on the ward (OR 2.4; $1.5-3.9 \mathrm{CI}$ ) and death after 3 months (OR 1.4; 0.7-3.4 CI) [5]. Immediately after awakening and extubation, Monk found a 3.7\% incidence of ED, declining to $1.3 \%$ when re-evaluated in the PACU [6]. Another study found a $4 \%$ incidence of ED at the time of discharge from the PACU [7]. In contrast to $\mathrm{ED}$, hypoactive POD has subtle symptoms and is even more frequent. To detect POD in the PACU, objective tools, like pupillometry or processed electroencephalography were evaluated but are still not implemented into clinical practice $[8,9]$. Today, a standardised delirium screening as proposed by Radtke et al. [4] and the recent European Guideline on delirium, published after this survey was performed [10], underlines the importance of screening for POD in all surgical patients. Screening should already start in the PACU and should be carried out in each shift up to postoperative day 5 with a validated score [10]. Besides the scientific studies that led to the development of the current guideline, there is no research or data outlining current strategies for POD management in the PACU. However, a detailed insight into the characteristics of clinical practice would be extremely fruitful for a successful future implementation of these guidelines [11].

To date, there are no data concerning organisational strategies and current practice in terms of delirium prophylaxis, use of delirium tools for screening and concerning delirium therapy in German PACUs. In order to achieve this information, we designed a prospective, German-wide online survey.

Our primary hypothesis was, that independently of the later recommendation to screen for delirium in the PACU, such a screening was not implemented at the time of the survey. Our secondary hypothesis was, that, nevertheless, medical prophylaxis and therapy of delirium is state of the art in German PACUs.

\section{Methods}

This manuscript documents German standards in postoperative care via an online survey [12], meeting the COREQ criteria for the reporting of qualitative studies [13]. After reconciliation and approval by the ethics committee, Faculty of Medicine, LMU Munich, a mailing list provided by the German Society of Anaesthesiology and Intensive Care Medicine (DGAI) and the German Anaesthesiologists Association (BDA) was used to invite 922 heads of departments or anesthesiologists otherwise in an executive position for at least one of the 1173 heads of departments in German hospitals and 726 anesthesiologists working in an ambulatory setting to take part in the electronic survey (LimeSurvey 2.05 software package, LimeSurvey $\mathrm{GmbH}$, Hamburg, Germany) by a single-use link sent by email. To remove responder bias, the questionnaire was re-sent once. In a short introduction we explained the significance of delirium monitoring in critical and postoperative care and the objective of the study. Informed consent was obtained before the 25 questions could be answered anonymously. All participation data, necessary for an email reminder, were erased after the completion of the survey.

\subsection{Statistical analysis}

In order to estimate the relevant percent or proportion, results are being presented as correlation of the answers to the total cohort together with a 95\%-confidence interval, calculated by the Clopper-Pearson method. For comparing means, the Mann-Whitney-U-Test was used. Categorical data were analysed by the $\mathrm{X}^{2}$-test or Fisher's exact test, determining the level of significance as $a=5 \%$. To show reach and frequencies of different recommendations for delirium screening, a Total Unduplicated Reach and Frequency (TURF) analysis $[14,15]$ was executed. TURF analyses are typically used for market research. They are useful to identify the optimal design in a combination of products to achieve a maximum of distribution (range) and sales (frequencies). Adopted on screening methods in medicine, a TURF analysis enables the examination of the total acceptance for a multi-component measure by a combination of separate subgroups. For statistical analysis we used SPSS Statistics for Macintosh 25 (IBM Corp., Armonk, NY, USA).

\section{Results}

\subsection{Structural data}

The survey was open for participation between 4th of May and 21st of June 2015. Participation was 30\% among hospital anesthesiologists $(n=275 / 922)$ and 6\% among ambulatory surgery anesthesiologists $(n=44 / 726)$. Due to the low response rate in this subgroup, results are displayed for the whole group of anesthesiologists. Five participants declined to participate or opted out. 292 completed the questionnaire. Questions only referring to PACU care were answered by 276 anesthesiologists. Of these responders, 70 [95\%-confidence interval 65-76] \% were head of their department, 18 [14-23] \% senior consultants and 12 [8-16] \% other physicians. $237(86[81-90] \%)$ of the anesthesiologists worked at a 
Table 1 Number of anesthetic procedures per year among the participants

\begin{tabular}{lrc}
\hline $\begin{array}{l}\text { Anesthetic procedures per } \\
\text { year }\end{array}$ & Frequency & $\begin{array}{l}\text { Percentage, } \\
\text { ratio }(\%)\end{array}$ \\
\hline $0-2500$ & 43 & 14.7 \\
$2501-5000$ & 67 & 22.9 \\
$5001-15,000$ & 143 & 49.0 \\
$15,001-30,000$ & 30 & 10.3 \\
$30,001-45,000$ & 5 & 1.7 \\
$>45,000$ & 4 & 1.4 \\
Total & 292 & 100.0 \\
\hline
\end{tabular}

Table 2 Presence of an anesthesiologist in the PACU related to PACU capacity

\begin{tabular}{ll}
\hline Number of PACU beds & $\begin{array}{l}\text { Physician presence in the } \\
\text { PACU }(\mathrm{n}=49), \text { ratio }(\%)\end{array}$ \\
\hline $1-4$ & 26.5 \\
$5-9$ & 13.8 \\
$10-19$ & 16.5 \\
$20-29$ & 33.3 \\
$>30$ & $75.0^{\mathrm{a}}$ \\
\hline
\end{tabular}

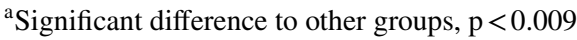

hospital, 39 (14 [10-19] \%) in an outpatient setting. 19 (7 [4-10] \%) worked at a university hospital, 39 (13 [10-18] $\%$ ) were associated with a university at a teaching hospital. Further structural data on the responders were published before [11], see also Table 1 .

\subsection{Organisational strategies regarding delirium in the PACU}

In 19 [14-24] \% of the hospitals, permanent medical care by a physician was exclusively provided for the PACU (Table 2). The continuous presence of an anesthesiologist was reported in $>75 \%$ only in hospitals with more than 30 PACU beds and more than 45,000 procedures per annum.

In 10 [6-14] \% of the participating hospitals a structured delirium screening was being provided postoperatively in the PACU.

To detect a delirious state, $44 \%$ of the anesthesiologists who routinely score for delirium, used one of the two recommended tools at the PACU for in- as well as outpatient care: the Confusion Assessment Method for the Intensive Care Unit (CAM-ICU; 11 [8-16] \%) and the Nursing Delirium Screening Scale (NuDESC 12 [8-17] \%). 5\% even had two tools in use (see Table 3). 65 [59-70] \% of the respondents did not use any score at all. Patients diagnosed positively for delirium were mostly transferred to an intensive care unit (72 [66-77] \%); 16 [12-20] \% were transferred
Table 3 Instruments used for delirium detection in the PACU

\begin{tabular}{lll}
\hline Screening instrument & Totals & Ratio (\%) \\
\hline CAM (Confusion Assessment Method) & 10 & 3.6 \\
CAM-ICU (CAM for the Intensive Care Unit) & 27 & 9.7 \\
DDS (Delirium Detection Scale) & 7 & 2.5 \\
DRS-R98 (Delirium Ratings Scale Revised 98) & 0 & - \\
ICDSC (Intensive Care Delirium Screening & 5 & 1.8 \\
$\quad$ Checklist) & & \\
NuDesc (Nursing Delirium Screening Scale) & 28 & 10.1 \\
DSM (Diagnostic and Statistical Manual of & 24 & 8.7 \\
$\quad$ Mental Disorders) or ICD-10 & & \\
PAED (Pediatric Anesthesia Emergence Delirium & 10 & 3.6 \\
Scale) & & \\
\hline
\end{tabular}

to a regular ward, despite being delirious. When delirium was diagnosed, $38 \%$ of the anesthesiologists in hospitals informed ward nurses about the delirium, $46 \%$ notified the physician in charge. To ensure individual postoperative care, 14 [10-19] \% of the responders organised an individual bedside observation or monitor for the delirious patient (12 [8-17] \%). In addition, 12 [8-17] \% of the responders consulted a psychiatrist.

\subsection{Delirium screening at hospitals wards}

In our survey at 77 [71-82] \% of the wards in participating hospitals, a delirium screening is carried out for at least one clinical condition (see Table 4), meaning one fourth of the participants would not screen for delirium under any

Table 4 Circumstances of delirium screening in general

\begin{tabular}{lcc}
\hline When delirium screening is performed $^{\mathrm{a}}$ & $\begin{array}{l}\text { Totals } \\
(\mathrm{n}=292)\end{array}$ & Ratio (\%) \\
\hline When delirium is suspected & 133 & 45.5 \\
As circumstances demand & 114 & 39.0 \\
Only in critically ill patients & 57 & 19.5 \\
Only when neurological abnormalities occur & 36 & 12.3 \\
Only postoperatively & 27 & 9.2 \\
Special care (e.g. stroke unit, chest pain unit) & 23 & 7.9 \\
Geriatric wards & 18 & 6.2 \\
ALL patients & 8 & 3.1 \\
Only in the elderly & 8 & 2.7 \\
On PACU discharge & 7 & 2.4 \\
Also in pediatric patients & 5 & $1.7^{\mathrm{b}}$ \\
On PACU admission and discharge & 5 & 1.7 \\
Normal care (ward) & 3 & 1.0 \\
Emergency room & 1 & 0.3 \\
\hline
\end{tabular}

${ }^{\text {a }}$ Response to the question "In what framework do you usually administer a delirium score?", multiple answers suitable

${ }^{\mathrm{b}}$ Significant difference to all groups $(\mathrm{p}=0.001)$ 


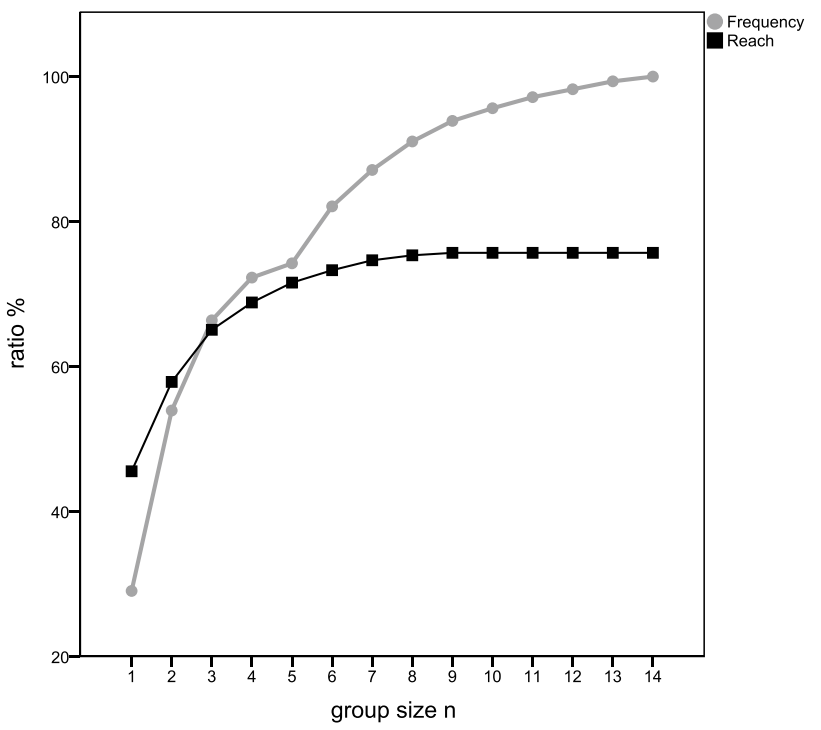

Fig. 1 TURF-analysis. In a weighted TURF-analysis on delirium screening for the relevant groups, recommendations for delirium screening fit German anesthesiologists' expectations in a maximum of 221 participants (75.7\%), if there was a recommendation for one or more of the following settings: delirious or noticeable neurological patients, elderly or geriatric patients, for in-hospital patients, particular or critical care, only postoperatively. It reaches $>95 \%$ of the patients and $>90 \%$ if "elderly" and "all patients" are excluded in a hospital cohort (220 participants, $75.3 \%$ ). The conjunction of the subgroups in the latter example shows, together with the graph, that even with a clear indication to establish screening for delirium for all subgroups as described in Table 4, 25\% of the participants have not been reached by any recommendation, meaning they would not screen any patient. Even in the traditional fields of critical care or when delirium is suspected, $65.1 \%$ participiants would administer a score

circumstances. Delirium screening was applied in only 46 [40-52] \% of the patients even when delirium was suspected. A TURF analysis showed that a maximum of $75 \%$ of all patients would be tested for delirium (Fig. 1).

\subsection{Pharmacological treatment of postoperative delirium in the PACU}

Neuroleptics were the drugs used in at least every fifth case of PACU delirium and in up to 77 [71-82] \% for patients with delusions (see Table 5), whereas atypical neuroleptics like quetiapin were rarely used in the PACU.

For anxiety, benzodiazepines were used in every second case. For vegetative symptoms caused by delirium, alpha2-agonists were administered in 83 [76-87] \% of all cases.

Physostigmine, the antidote for anticholinergic acting drugs (its use was not included in the questionnaire but was provided as a free-text answer for the therapy of PACU delirium) was applied specially to treat the hypoactive form of delirium by 12 [8-16] \% of the respondents. However, almost every second anesthesiologist did not treat hypoactive delirium.

\subsection{Preoperative strategies regarding delirium}

During preoperative evaluation, 43.1 [37.2-49.2] \% of all respondents in our survey informed patients about the possibility of a postoperative delirium.

\section{Discussion}

Our survey shows that delirium screening rates were low in German PACUs at least at the time, before German and European guidelines pleaded for postoperative delirium screening as a standard operating procedure for evidencebased practice. Several scientific studies (that had been published before 2015) providing evidence for high delirium rates in the PACUs [10] had not yet led to a cultural change in delirium management at that time.

Only $10 \%$ of the participating hospitals screened for delirium in the PACU. $10 \%$ of the respondents had
Table 5 Medication used for the therapy of delirium

\begin{tabular}{lcccl}
\hline $\begin{array}{l}\text { Medication used according indi- } \\
\text { vidual indication, ratio (\%) }\end{array}$ & $\begin{array}{l}\text { Vegetative } \\
\text { Symptoms }\end{array}$ & Anxiety & $\begin{array}{l}\text { Psychotic symptoms, } \\
\text { hyperactivity }\end{array}$ & $\begin{array}{l}\text { Hypo- } \\
\text { active } \\
\text { delirium }\end{array}$ \\
\hline Typical neuroleptics & 40.2 & 20.7 & 76.8 & 19.9 \\
Atypical neuroleptics & 4.3 & 3.6 & 15.6 & 13.8 \\
Long-acting benzodiazepines & 9.4 & 48.2 & 9.4 & 2.9 \\
Short-acting benzodiazepines & 22.8 & 40.6 & 19.2 & 6.5 \\
Alpha-2 agonists & 82.6 & 29.0 & 38.0 & 10.9 \\
Beta-blocker & 11.2 & 0.4 & 1.4 & 0 \\
Propofol & 14.5 & 10.5 & 11.6 & 1.1 \\
Physostigmine & 5.8 & 0.4 & 4.0 & 12.0 \\
No medication & 2.2 & 8.2 & 3.6 & 45.2 \\
\hline
\end{tabular}

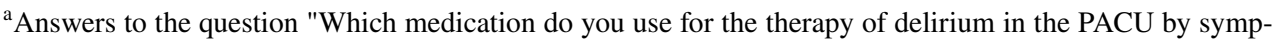
toms?". Total ratio (\%) of answers (multiple answers suitable) in all respondents 
implemented structured programs at their facilities. $46 \%$ used a tool to screen patients at least if delirium was suspected and two third of the anesthesiologists did not use a delirium score in the PACU at all. In contrast, in an ICU-setting $72 \%$ of the anesthesiologists already used a scoring system [11], which leads to the conclusion that delirium screening in the ICU is much better established as it is in PACUs. It is reasonable to expect, that with further promotion of the recently published European Guidelines, an increase in screening rates will take place in the PACU as well. The implementation of a delirium screening test into electronic PACU documentation systems could further improve this (Fig. 2). In a study conducted at our center, we achieved delirium screening rates of more than $70 \%$ by implementing the Nurse Delirium Screening Scale requested by the staff at discharge from the PACU (unpublished data, submitted for publication).

To really realize our deficiencies concerning the screening for delirium — elaborated in the present research — could be a first step towards improving the patients' worse outcome caused by delirium.

The second step should be to ensure the implementation of the guidelines. Therefore, information for all medical employees on delirium, e.g. with bedside teaching to the caregivers, is necessary. It has been documented that multicomponent programs for delirium prevention can reduce the incidence of delirium [16] and, in a geriatric population, the length of stay and hospital costs [17].

The introduction of an anesthetic protocol, designed to diminish adverse anesthetic effects, including delirium, is associated with a reduction of anesthetic recovery time [18] and thus reducing costs (about $10.80 €$ per minute for PACUs in a French study [19]). As a consequence, implementation of a structured protocol [20] for early delirium screening is cost-effective as it reduces PACU time and occupies fewer PACU nurses. A promising approach might be a standing order procedure, worked out by a multidisciplinary team of nurses, physicians and other experts, as the guidelines [10] suggest. A cue in the electronic documentation system could underline this order.

The third step would involve further raising awareness for the necessity of care for delirium among physicians as well as nurses and other caregivers. Our survey showed that in four out of five PACUs there is neither a physician permanently present nor did a structured delirium screening takes place (in 1 of 10 PACUs). Anesthesiologists on duty at the PACU - continuously as in university PACUs or on short call at others - could foster these considerations by acting as role models. Therefore, interdisciplinary communication between all personnel involved in delirium care would need to be improved as it has been identified as a major issue impeding successful guideline implementation [21].
Fig. 2 Example of delirium screening in electronic anesthesia documentation. The figure shows the interactive mask for the documentation of the NuDESC-delirium screening in the Narko Data ${ }^{\odot}$-monitor. University Hospital, LMU Munich

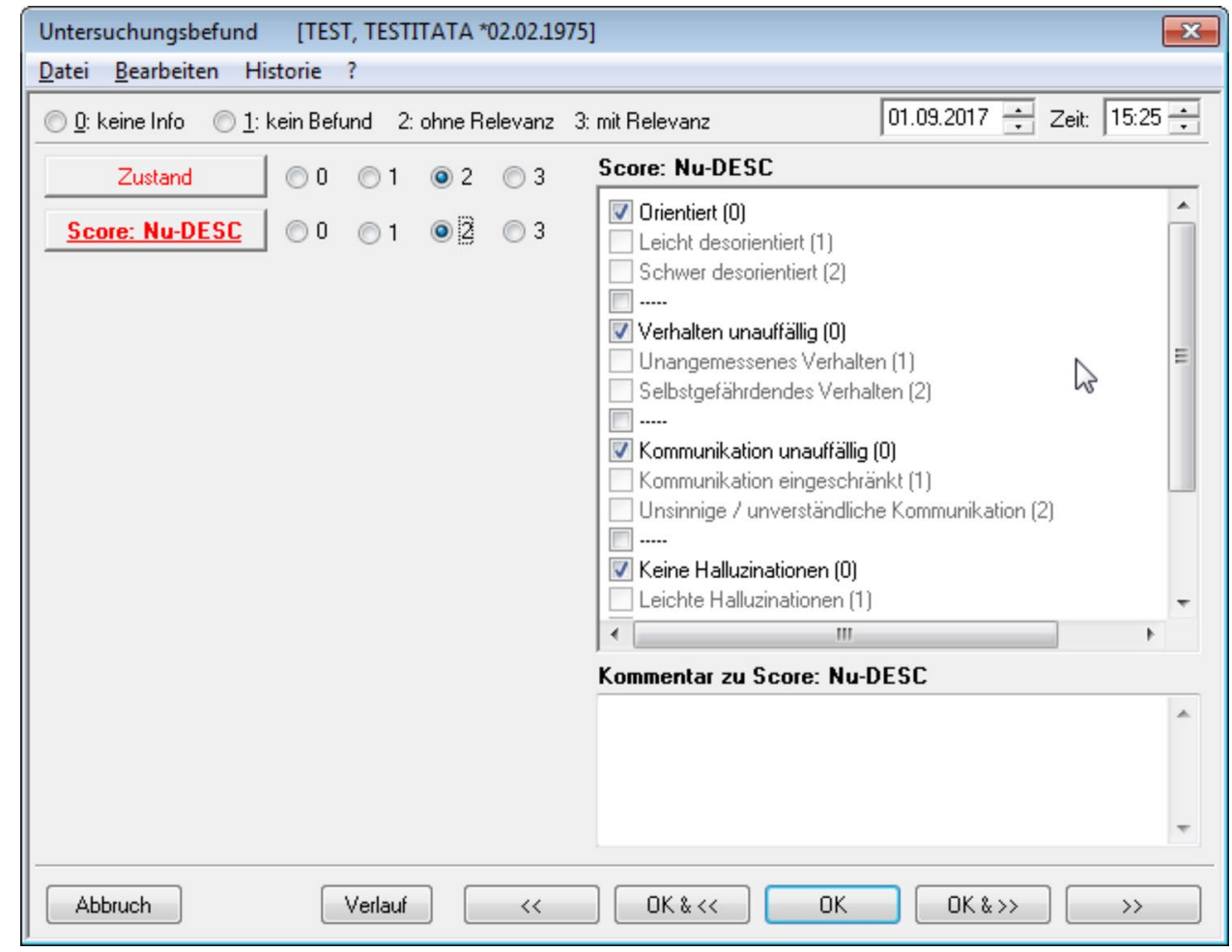




\subsection{Delirium on the ward}

Only every tenth hospital provided a structured screening for delirium at the time of the survey, $1 \%$ of the respondents practiced delirium screening in regular wards, $6 \%$ in geriatric wards and $10 \%$ in regular wards postoperatively. The severity and potential threat for patients is being recognised as $72 \%$ of delirious patients would be transferred to an intensive care unit for further care. If treatment on an ICU improves the non-pharmacological therapy of delirium is at least questionable.

Even if supposing that all patients at a hospital were screened, a maximum of $75 \%$ of the patients would be tested for delirium according to a TURF analysis [14] (Fig. 1). 25\% of the caregivers would not be reached by any recommendation. Including these caregivers might be one of the biggest challenges when putting the recently published European Guidelines [10] into practice.

\subsection{Therapy of Delirium}

Our study also showed that the therapy of delirium, once diagnosed, is very heterogeneous. The European Society of Anaesthesiology (ESA) recommendation for delirium therapy is to titrate haloperidol $0.25 \mathrm{mg}$-wise (level of recommendation 'B'). Participants in our study administered haloperidol in $20-80 \%$ of the delirious patients, mostly according to their delirium subtype. Most of the anesthesiologists confirm a pathophysiological approach to the therapy of delirium. However, only half of the respondents treated hypoactive delirium, the subtype most frequent and at the same time most difficult to identify. Consequently, one has to assume that most of the delirious patients (especially with hypoactive delirium) were not correctly diagnosed and accordingly obtained no correspondent therapy. That finding implies on what future research might put a focus.

\section{Limitations}

A qualitative online survey is a viable method for the identification of barriers to adherence to and implementation of guidelines [22]. In every qualitative study, however, a bias of social desirability must be assumed, thus possibly leading to more positive findings than a neutral observation of organizational practice could reveal. Since participation in an online survey can be carried out anonymously, false answers are negligible.

Neither surgeons nor nurses participated in the survey, thus, the results of this survey cannot be transferred to specialties other than anesthesiology. However, our work may overestimate the level of implementation by focusing on the expertise of leading physicians.

With 30\% for hospital anesthesiologists, its participation rate lies within a typical range for online surveys [12, 23] and fits the response rate of the same cohort [24]. Our respondents represent a fifth of all leading German anesthesiologists.

Our data reflect the German perspective of delirium management before the implementation of the ESA guideline in 2017 [10]. Further studies should now examine whether the publication of the guideline has changed delirium management. Lastly, one would need to discuss, while taking into consideration the differences in health systems and intercultural issues, how these results might be transferable to other national contexts.

\section{Conclusion}

The aim of this study was to understand organisational practices concerning PACU medical personnel and strategies for delirium screening and therapy in German PACUs in hospitals and ambulatory anesthesia facilities. Only $10 \%$ of the participating hospitals in our survey provided a structured delirium screening for their postoperative patients in the PACU. If already implemented, validated scores were used. The hypoactive form of delirium was rarely treated with any medication.

Our results show furthermore that standards for delirium prophylaxis and screening in the PACU were low before the publication of the ESA guidelines [10]. According to these evidence-based and consensus-based guidelines on postoperative delirium, patients should not leave the PACU without having been screened for POD and screening is recommended up to the 5th postoperative day [10].

Future studies should examine implementation rates at short intervals in order to reveal obstacles in applying these guidelines.

Acknowledgements We would like to thank the office of the German Society of Anaesthesiology and Intensive Care Medicine (DGAI), Mr. Holger Sorgatz and Mrs. Monique Minde (Nuremberg, Germany) for their kind support in the preparation and execution of the survey, and Prof. Gernot Marx (Department of Intensive Care and Intermediate Care, RWTH University Hospital Aachen, Aachen, Germany) on behalf of the DGAI intensive care working committee for his permission to conduct the study and his kind support.

Author contributions TS and IS designed the questionnaire, TS performed the survey, analysed the data and wrote the draft of the manuscript. KHK, IS, BZ and VvD approved the questionnaire, discussed the data, proofread and rewrote the manuscript. All authors have read and approved the manuscript. 


\section{Compliance with ethical standards}

Conflict of interest BZ is acting secretary-general of the German Society of Anaesthesiology and Intensive Care Medicine (DGAI); KHK, IS, VvD, TS: None.

Ethical approval The study was approved by the ethics committee, Faculty of Medicine, LMU Munich, on March 24th 2015 (reference number 180-15). Written informed consent was waived by the ethics committee. However, every participant clearly stated her or his will to participate by activating a checkbox in the online tool.

Open Access This article is licensed under a Creative Commons Attribution 4.0 International License, which permits use, sharing, adaptation, distribution and reproduction in any medium or format, as long as you give appropriate credit to the original author(s) and the source, provide a link to the Creative Commons licence, and indicate if changes were made. The images or other third party material in this article are included in the article's Creative Commons licence, unless indicated otherwise in a credit line to the material. If material is not included in the article's Creative Commons licence and your intended use is not permitted by statutory regulation or exceeds the permitted use, you will need to obtain permission directly from the copyright holder. To view a copy of this licence, visit http://creativecommons.org/licenses/by/4.0/.

\section{References}

1. Deutsche Gesellschaft für Anästhesiologie und Intensivmedizin und Berufsverband Deutscher Anästhesisten (2009) Überwachung nach Anästhesieverfahren. Anaesthesiol Intensivmed 50:S486-9.

2. Sharma PT, Sieber FE, Zakriya KJ, Pauldine RW, Gerold KB, Hang J, Smith TH. Recovery room delirium predicts postoperative delirium after hip-fracture repair. Anesth Analg. 2005;101(4):1215-20. https://doi.org/10.1213/01.ane.00001 67383.44984.e5

3. Radtke FM, Franck M, Schust S, Boehme L, Pascher A, Bail HJ, Seeling M, Luetz A, Wernecke KD, Heinz A, Spies CD. A comparison of three scores to screen for delirium on the surgical ward. World J Surg. 2010;34(3):487-94. https://doi.org/10.1007/ s00268-009-0376-9.

4. Radtke FM, Franck M, Schneider M, Luetz A, Seeling M, Heinz A, Wernecke KD, Spies CD. Comparison of three scores to screen for delirium in the recovery room. Br J Anaesth. 2008;101(3):338 43. https://doi.org/10.1093/bja/aen193.

5. Stukenberg S, Franck M, Spies CD, Neuner B, Myers I, Radtke FM. How can postoperative delirium be predicted in advance? A secondary analysis comparing three methods of early assessment in elderly patients. Minerva Anestesiol. 2016;82(7):751-9.

6. Kinjo S, Lim E, Magsaysay MV, Sands LP, Leung JM, Perioperative Medicine Research G. Volatile anaesthetics and postoperative delirium in older surgical patients-a secondary analysis of prospective cohort studies. Acta Anaesthesiol Scand. 2019;63(1):18 26. https://doi.org/10.1111/aas.13227.

7. Card E, Pandharipande P, Tomes C, Lee C, Wood J, Nelson D, Graves A, Shintani A, Ely EW, Hughes C. Emergence from general anaesthesia and evolution of delirium signs in the postanaesthesia care unit. Br J Anaesth. 2015;115(3):411-7. https:// doi.org/10.1093/bja/aeu442.

8. Yang E, Kreuzer M, Hesse S, Davari P, Lee SC, Garcia PS Infrared pupillometry helps to detect and predict delirium in the post-anesthesia care unit. J Clin Monit Comput. 2018;32(2):359 68. https://doi.org/10.1007/s10877-017-0009-z.

9. Numan T, van den Boogaard M, Kamper AM, Rood PJT, Peelen LM, Slooter AJC, Dutch Delirium Detection Study G. Delirium detection using relative delta power based on 1-minute singlechannel EEG: a multicentre study. Br J Anaesth. 2019;122(1):60 8. https://doi.org/10.1016/j.bja.2018.08.021.

10. Aldecoa C, Bettelli G, Bilotta F, Sanders RD, Audisio R, Borozdina A, Cherubini A, Jones C, Kehlet H, MacLullich A, Radtke F, Riese F, Slooter AJ, Veyckemans F, Kramer S, Neuner B, Weiss B, Spies CD. European Society of Anaesthesiology evidence-based and consensus-based guideline on postoperative delirium. Eur J Anaesthesiol. 2017;34(4):192-21414. https://doi. org/10.1097/EJA.0000000000000594.

11. Saller T, von Dossow V, Hofmann-Kiefer K. Knowledge and implementation of the $\mathrm{S} 3$ guideline on delirium management in Germany. Der Anaesthesist. 2016;65(10):755-62. https://doi.org/ 10.1007/s00101-016-0218-8.

12. Thielsch MT, Weltzin S. Online-Befragungen in der Praxis. In: Brandenburg T, Thielsch M, editors. Praxis der Wirtschaftspsychologie, vol 1. Themen und Fallbeispiele für Studium und Anwendung. Münster: Verlagshaus Monsenstein und Vannerdat OHG Münster; 2009.

13. Tong A, Sainsbury P, Craig J. Consolidated criteria for reporting qualitative research (COREQ): a 32-item checklist for interviews and focus groups. Int J Qual Health Care. 2007;19(6):349-57. https://doi.org/10.1093/intqhe/mzm042.

14. Conklin WM, Lipovetsky S. Marketing decision analysis by Turf and Shapley value. Int J Inf Technol Decis Making. 2011;04(01):5-19. https://doi.org/10.1142/s0219622005001374.

15. Serra D (2010) A new model for designing a product line using TURF analysis. Barcelona Economics Working Paper Series (433): 20

16. Siddiqi N, Harrison JK, Clegg A, Teale EA, Young J, Taylor J, Simpkins SA. Interventions for preventing delirium in hospitalised non-ICU patients. Cochrane Database Syst Rev. 2016. https://doi. org/10.1002/14651858.CD005563.pub3.

17. Zaubler TS, Murphy K, Rizzuto L, Santos R, Skotzko C, Giordano J, Bustami R, Inouye SK. Quality improvement and cost savings with multicomponent delirium interventions: replication of the Hospital Elder Life Program in a community hospital. Psychosomatics. 2013;54(3):219-26. https://doi.org/10.1016/j.psym.2013. 01.010 .

18. Weingarten TN, Bergan TS, Narr BJ, Schroeder DR, Sprung J. Effects of changes in intraoperative management on recovery from anesthesia: a review of practice improvement initiative. BMC Anesthesiol. 2015;15:54. https://doi.org/10.1186/ s12871-015-0040-x.

19. Raft J, Millet F, Meistelman C. Example of cost calculations for an operating room and a post-anaesthesia care unit. Anaesth Crit Care Pain Med. 2015;34(4):211-5. https://doi.org/10.1016/j. accpm.2014.11.002.

20. Merkel MJ, von Dossow V, Zwissler B. Structured patient handovers in perioperative medicine: rationale and implementation in clinical practice. Der Anaesthesist. 2017;66(6):396-403. https:// doi.org/10.1007/s00101-017-0320-6.

21. Boehm LM, Vasilevskis EE, Mion LC. Interprofessional perspectives on ABCDE bundle implementation: a focus group study. Dimens Crit Care Nurs. 2016;35(6):339-47. https://doi.org/10. 1097/DCC.0000000000000208.

22. Trogrlic Z, Ista E, Ponssen HH, Schoonderbeek JF, Schreiner F, Verbrugge SJ, Dijkstra A, Bakker J, van der Jagt M. Attitudes, knowledge and practices concerning delirium: a survey among intensive care unit professionals. Nurs Crit Care. 2017;22(3):13340. https://doi.org/10.1111/nicc.12239. 
23. Scholten HJ, Ten Bloemendal E, Botter B, Korsten HHM, Bouwman RA. Barriers to ultrasound guidance for central venous access: a survey among Dutch intensivists and anaesthesiologists. J Clin Monit Comput. 2019. https://doi.org/10.1007/ s10877-018-00246-z.

24. Defosse J, Schieren M, Bohmer A, von Dossow V, Loop T, Wappler F, Gerbershagen MU. A Germany-wide survey on anaesthesia in thoracic surgery. Der Anaesthesist. 2016;65(6):449-57. https:// doi.org/10.1007/s00101-016-0175-2.
25. Duran CE, Azermai M, Vander Stichele RH. Systematic review of anticholinergic risk scales in older adults. Eur J Clin Pharmacol. 2013;69(7):1485-96. https://doi.org/10.1007/s00228-013-1499-3.

Publisher's Note Springer Nature remains neutral with regard to jurisdictional claims in published maps and institutional affiliations. 